Cite this: RSC Adv., 2017, 7, 13836

Received 14th October 2016 Accepted 16th February 2017

DOI: $10.1039 / c 6 r a 25237 k$

rsc.li/rsc-advances

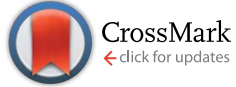

\section{Facile synthesis of $\mathrm{KCl}: \mathrm{Sm}^{3+}$ nanophosphor as a new OSL dosimetric material achieved through charge transfer between the defect states}

\begin{abstract}
Mini Agarwal, ${ }^{a}$ S. K. Garg, ${ }^{\text {b K. Asokan, }}{ }^{\text {b D. Kanjilal }}{ }^{\text {b }}$ and Pratik Kumar ${ }^{\star a}$
Since precise control of nanoscale features is in high demand, it is being exploited to develop and improve OSL dosimetric materials, where striking improvement might also be expected in lanthanide-doped metal halides. The major challenge in the development of a nanophosphor lies in avoiding the aggregation of a dopant element in host materials, which has long prevented an in-depth exploration for the same purpose. This study focuses on the synthesis and characterization of Sm-doped $\mathrm{KCl}$ nanophosphors to develop a novel accession to investigate the highly sensitive trivalent $\mathrm{Sm}$-doped $\mathrm{KCl}$ phosphor. Herein, we were able to overcome the aggregation phenomena and we showed that Sm-doped $\mathrm{KCl}$ with 0.45 mol\% of Sm, which is the optimised dopant concentration, exhibits the high-intensity luminescence performance under blue light stimulation for the gamma doses in the range from 100 mGy to 1000 Gy. This sensitivity is attributed to the uniform nanospheres encapsulated in $\mathrm{KCl}$ along with the predominant existence of a trivalent $\left(\mathrm{Sm}^{3+}\right)$ state, where these conditions can introduce additional defects centres. The presence of these additional defect centres was confirmed by photoluminescence studies, plausibly supporting the charge transfer due to the optical energy between these states, leading to high sensitivity. To establish $\mathrm{KCl}: \mathrm{Sm}$ as a good OSL dosimetric materials (DM), we investigated fading, reusability, and reproducibility and compared these with those of commercial $D M$ compounds such as $\mathrm{Al}_{2} \mathrm{O}_{3}: \mathrm{C}$ and $\mathrm{BeO}$. Overall, $\mathrm{Sm}$-doped $\mathrm{KCl}$ is non-toxic, cost-effective, robust, and a promising candidate for reusable dosimetry.
\end{abstract}

\section{Introduction}

The optically stimulated luminescence (OSL) technique-based medical dosimetry is attracting significant attention compared to thermoluminescence (TL) technique due to the advantages such as cost-effectiveness, fast to read, and easy to handle. Optically excited materials emit a significant amount of luminescence without producing adverse effects such as complete photoionization of defects; hence, the guard detector is available for many readings without destroying the signal. ${ }^{1}$ The OSL signal originates from the recombination centres/luminescence centres existing deep in the forbidden band gap, where electrons combine with holes at neutral and charged vacancies/ colour centres $\mathrm{F}$ and $\mathrm{F}^{+}$, respectively. ${ }^{2}$ This is an outcome of illumination on the pre-irradiated detector material, which excites the electrons from moderate defect centres to the conduction band; therefore, the whole process largely depends on the electronic structure of the material in association with electron and hole defect centres at various energy depths. ${ }^{3}$ Some of the radiation-generated holes become trapped at the

${ }^{a}$ Medical Physics Unit, IRCH, AIIMS, New Delhi-110 029, India. E-mail: drpratikkumar@gmail.com

${ }^{b}$ Inter-University Accelerator Centre, Aruna Asaf Ali Marg, New Delhi-110 067, India recombination centres known as $\mathrm{F}^{+}$centres $\left(\mathrm{F}+\mathrm{h}^{+} \rightarrow \mathrm{F}^{+}\right)$. When the phosphor is optically stimulated by blue LEDs light of $470 \mathrm{~nm}$, electrons depopulate from the electron trap centres and through the conduction band recombine with holes at the $\mathrm{F}^{+}$trap centres, resulting in radiative luminescence of $420 \mathrm{~nm}$ $\left(\mathrm{F}^{+}+\mathrm{e}^{-} \rightarrow \mathrm{F}^{*}+h \nu_{420 \mathrm{~nm}}\right)^{4}$

In the continuous search of better OSL materials to overcome the issues such as fading, low efficiency, compromised reusability, imperfect reproducibility, high-cost, high effective atomic number, tissue in-equivalency etc., a few OSL phosphors have been reported. These include oxides, halides, silicates, ammonium salts, sulphates, and aluminates. ${ }^{5}$ These phosphors were prepared by the introduction of a foreign dopant in the host matrix with its (dopant) precise concentration, where better control of the luminescence properties was achieved by exploiting its nanoscale features, which was quite difficult due to the agglomerative nature of the dopant. ${ }^{6}$ However, these phosphors suffer from one or more drawbacks that make these less favourable for dosimetric applications. The best known and commercially available OSL materials $\mathrm{Al}_{2} \mathrm{O}_{3}: \mathrm{C}$ and $\mathrm{BeO}$ are used as personal dosimeters despite the complexities in their synthesis process. ${ }^{7}$ For example, accurate carbon doping without aggregation in alumina under a reducing atmosphere of graphite at very high temperature is a demanding 
condition.,.$^{5,8}$ Other near tissue-equivalent materials such as aluminates and silicates have been found to suffer from the limitations of high fading of about $80 \%$ within a month and are highly hygroscopic in nature. ${ }^{9}$ Compared to commercial $\mathrm{Al}_{2} \mathrm{O}_{3}$ :C, a much lower sensitivity was achieved for $\mathrm{LiAlO}_{2}: \mathrm{Cu}, \mathrm{P}$ and MgO:Tb. ${ }^{10}$ Ammonium salts and Fluorosilicates such as $\mathrm{NH}_{4} \mathrm{Br}$ and $\left(\mathrm{NH}_{4}\right)_{2} \mathrm{SiF}_{6}$ have also been reported to suffer from the higher fading of more than $80 \%$ within 10 hours. Fluorides such as $\mathrm{NaMgF}_{3}: \mathrm{Ce}$ and $\mathrm{KMgF}_{3}: \mathrm{Ce}$,Eu despite having good OSL sensitivity of about 7-8 times than that of commercial $\mathrm{Al}_{2} \mathrm{O}_{3}$ :C could not be adopted for personal dosimetry due to high selfdose and fading. ${ }^{5}$ Hence, there is enough scope and motivation to develop suitable personal OSL dosimetric material.

Recently, halides have emerged as potential OSL materials for two-dimensional (2D) imaging in medical diagnostics, radiation therapy, and a routine check of dosimetric parameters. ${ }^{11}$ These materials show a great storing efficiency and reusability, which are desirable properties in radiation therapy. ${ }^{12}$ BaFBrI:Eu and CsBr storage phosphor plates were designed for diagnostic radiology in the dose range of $\mu \mathrm{Gy}-$ mGy. However, these materials have a high $Z_{\text {eff }}(49)$ and show undesirable strong photon energy dependence. ${ }^{13} \mathrm{KBr}$ :Eu and $\mathrm{KCl}:$ Eu do not show any photon energy dependence and also exhibit less fading in the dark at room temperature. ${ }^{\mathbf{1 4}}$ On the other hand, the low-cost halide material $\mathrm{KCl}$, which is abundantly found in nature, has a lower effective atomic number than that of other storage phosphors such as $\mathrm{BaFBr}, \mathrm{KBr}$, etc., making it more suitable for radiation dosimetry. ${ }^{\mathbf{1 1}}$ Moreover, the lattice of $\mathrm{KCl}$ (highly ionic material) is face-centred cubic and exhibits a high melting point $\left(770^{\circ} \mathrm{C}\right)$, which allow for its use under extreme temperature conditions. Most of the properties of $\mathrm{KCl}$, such as a wide band gap $(\sim 8.5 \mathrm{eV})$ are profoundly influenced by the coulomb interactions, which makes it suitable to generate defect centers in the forbidden band gap by introducing foreign dopant atoms. Note that Sm (lanthanide) as a dopant in insulators/inorganic compounds offer high luminescence efficiency due to narrow emission bands and insufficient absorption in ultraviolet (UV-A) regions. Lanthanide ion (especially Sm)-doped phosphors have shown important and substantial optical and chemical properties on the nanoscale level, ${ }^{15}$ associated with more than one oxidation state; for instance, Kusaba et al. reported the direct excitation of lanthanides ions via charge transfer $4 \mathrm{f} \rightarrow 5 \mathrm{~d}$, which is responsible for inducing the photoreduction of $\mathrm{Sm}^{3+}$ to $\mathrm{Sm}^{2+} \cdot{ }^{\mathbf{1 6}}$ Therefore, we expected that $\mathrm{Sm}$ as a dopant may improve the fading in halide-based materials achieved via a hightemperature solid state synthesis method that leads to thermodynamically stable materials such as oxides, halides etc. ${ }^{\boldsymbol{6} \boldsymbol{b}}$ For instance, in the present work we observed that $\mathrm{KCl}: \mathrm{Sm}$ nanophosphor can measure the doses from 100 mGy to 750 Gy with a linear response and with the estimated minimum detectable dose $\sim 6.8 \mu \mathrm{Gy}$ due to the incorporation of trivalent $\mathrm{Sm}^{3+}$. The present investigation focused on the solid state synthesis of Sm-doped $\mathrm{KCl}$ nanophosphors with better OSL dosimetric properties and the systematic series of investigation indicated $\mathrm{KCl}: \mathrm{Sm}$ as a new OSL dosimetric phosphor in this first report.

\section{Material and methods}

\subsection{Material synthesis}

Sm-doped nanocrystalline $\mathrm{KCl}$ was synthesised by a solid state reaction at a high temperature of $200{ }^{\circ} \mathrm{C}$ for 3 hours with highquality precursors $\mathrm{KCl}(\mathrm{M} / \mathrm{S}$ Merck, AR grade, $99.95 \%$ pure) and $\mathrm{SmCl}_{2} \cdot 6 \mathrm{H}_{2} \mathrm{O}\left(\mathrm{M} / \mathrm{S}\right.$ Alfa Aesar, 99.5\% pure). ${ }^{17}$ During the synthesis, $\mathrm{KCl}$ was mixed with various concentrations of dopant precursor Sm such as $0.15,0.25,0.45$, and $0.50 \mathrm{~mol} \%$ to investigate the role of the Sm concentration for OSL applications. A finely ground homogenous mixture of prepared powder was subjected to a thermal treatment at 353-363 K for 3 hours to obtain fine nanophosphor. In addition, the mixture was then annealed (thermally) in a muffle furnace at various temperatures for 2 hours (from 950 to $1050 \mathrm{~K}$ ) at the heating rate of $15{ }^{\circ} \mathrm{C}$ per minute. In situ cooling of the mixture up to $573 \mathrm{~K}$ was achieved by keeping it in the furnace for about 20 minutes after switching off the furnace as per the suggestion prescribed by other workers. ${ }^{18}$ After this, the powder was taken out from the furnace and was kept on an alumina plate at room temperature. The powder and pellet form of the same mixture was used for further studies.

\subsection{Characterization}

High-resolution transmission electron microscopy (HRTEM) was performed on the newly synthesised $\mathrm{KCl}$ :Sm using TECNAI $\mathrm{G}^{2}$ HR-TEM, $200 \mathrm{kV}$, FEI Company, Holland. To examine the elemental composition and oxidation states of the prepared phosphor, X-ray photoelectron spectroscopy (XPS) was performed using an Omicron Nanotechnology, Oxford Instruments, Mistral USC at the ultra-high vacuum of $5 \times 10^{-10}$ bar. A monochromatized excitation source with X-ray photon energy (Al K $\alpha: 1486.7 \mathrm{eV}$ ) was used with an analyser pass energy of $50 \mathrm{eV}$ at the high-resolution scan (HR) at $20 \mathrm{eV}$. Photoluminescence (PL) measurements were carried in the wavelength range of 200-950 nm (for both excitation and emission, separate monochromator) using a xenon flash lamp. The light signal was detected by a photon counting system with a red sensitive photomultiplier tube with the wavelength accuracy of $\pm 0.1 \mathrm{~nm}$ at 200-950 $\mathrm{nm}$. All spectra were obtained with the limiting resolution of less than $1.5 \mathrm{~nm}$ using a solid state fluorescence spectrometer. X-ray diffractometer (XRD, D8 advance, Bruker, Germany) was employed with the monochromatic $\mathrm{Cu}-\mathrm{K}_{\alpha}$ radiation at the scan rate of $1.0 \mathrm{~s}$ per step at room temperature for the range of $2 \theta=20-80^{\circ}$ with a step size of $0.01^{\circ}$.

Continuous-wave optically stimulated luminescence (CWOSL) decay curves were obtained using a RISO TL/OSL reader (model TL/OSL-DA-20 from M/S DTU Denmark) at room temperature. The RISO reader was armed with blue LEDs, green LEDs, and IR LEDs (NICHIA type NSPB-500AS) for stimulation; blue LEDs (for detail study) with stimulation at the wavelength of $470 \mathrm{~nm}(\mathrm{FWHM}=20 \mathrm{~nm})$ and a power output of $\sim 4.8 \mathrm{~cd}$ at 20 $\mathrm{mA}$ were used. In this equipment, blue LEDs were arranged in 4 clusters with 7 individuals LEDs each, which deliver a total power of $80 \mathrm{~mW} \mathrm{~cm} \mathrm{~cm}^{-2}$ at the sample position. To achieve the best detection of OSL signal, a combination of filters such as 
green long pass filter (GG-420 with $3 \mathrm{~mm}$ thickness) in front of blue LED cluster and UV transmitting broadband (Hoya U-340) detection filter were used..$^{19}$ Low and high dose irradiation of the OSL phosphor was carried out using a RISO in situ beta irradiation source $\left({ }^{90} \mathrm{Sr} /{ }^{90} \mathrm{Y}\right)$ at the fixed dose rate of $3 \mathrm{mGy} \mathrm{s}^{-1}$ and an external gamma source $\left({ }^{137} \mathrm{Cs}\right)$ at the dose rate of 11.7 $\mathrm{cGy} \mathrm{s}^{-1}$. The OSL decay curves of an $8 \mathrm{mg}$ luminescence phosphor were obtained just after irradiation to avoid the fading issue.

\section{Results and discussions}

To completely understand the present proposed material $\mathrm{KCl}: \mathrm{Sm}$, synthesised by the high-temperature solid-state synthesis method, as an OSL dosimetry material, we divided the present section into two parts: (1) structural and morphological characterization and (2) OSL measurement, followed by discussion.

\subsection{Structural characterization}

The XRD patterns of KCl (pristine) and KCl:Sm shown in Fig. 1 evidence that these compounds are crystalline in nature with a face-centred cubic KCl structure and exhibit peaks at $2 \theta=$ $28.34^{\circ}, 40.5^{\circ}, 50.18^{\circ}, 58.6^{\circ}, 66.36^{\circ}$, and $73.72^{\circ}$ that were indexed to (200), (220), (222), (400), (420), and (422), respectively. ${ }^{20}$ All peaks in $\mathrm{KCl}: \mathrm{Sm}(0.45 \mathrm{~mol} \%)$ are similar to those of the pristine material, indicating a similar structure to that of KCl. While the intensities of peaks (200) and (400) were reduced, the peaks at (220), (222), (420), and (422) showed an increase in intensities with Sm doping, implying the improvement in crystallinity in one direction (220) at the cost of the other (200). A close inspection of the data revealed a small shift of $(\sim 2 \theta= \pm 0.6)$ in all the peak positions of $\mathrm{KCl}: \mathrm{Sm}$ with respect to those of pristine $\mathrm{KCl}$, implying that the generation of stress in $\mathrm{KCl}: \mathrm{Sm}$ may be due to the presence of $\mathrm{Sm}$ in the $\mathrm{KCl}$ matrix. In this study, Sm doping at low concentrations in $\mathrm{KCl}$ did not alter the crystallinity [data not shown]. Moreover, the average grain size corresponding to the (200) peak was estimated, which was approximately 20-60 nm, using the Debye-Scherrer formula:

$$
D=0.9 \lambda / \beta \cos \theta
$$

where $D$ is the average grain size of the crystallites, $\lambda$ is the incident wavelength of $\mathrm{Cu}-\mathrm{K}_{\alpha}$ radiation, $\beta$ is the diffracted full-

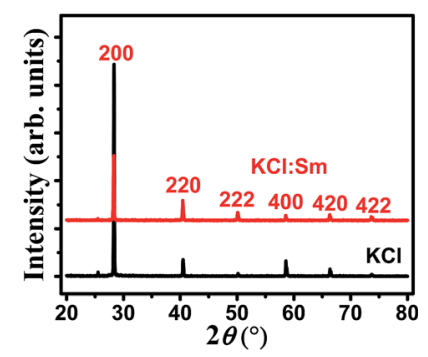

Fig. $1 \mathrm{X}$-ray diffraction patterns of pristine $\mathrm{KCl} \&(0.45 \mathrm{~mol} \%)$ samarium-doped $\mathrm{KCl}$. width at half maximum (radians) caused by the crystallites, and $\theta$ is the Bragg angle. Thus, $\mathrm{XRD}$ results confirmed that $\mathrm{KCl}: \mathrm{Sm}$ is crystalline with a face-centred cubic $\mathrm{KCl}$ structure.

TEM images along with selective-area diffraction (SAD) pattern as a function of the dopant concentration before and after irradiation are shown in Fig. 2. The average particle size was found in the range of 90-190 nm for pristine KCl [Fig. 2(a)], KCl:Sm (0.15 mol\%) [Fig. 2(b)], and KCl:Sm (0.25 mol\%) [image not shown]. Further increase in the dopant concentration to $0.45 \mathrm{~mol} \%$ resulted in an average isolated particle size of 20$60 \mathrm{~nm}$ with a variation in particle shape (spherical and cubic), as shown in Fig. 2(c). A further slight increment in the dopant concentration (e.g. 0.50 mol\%, Fig. $2(\mathrm{~d})$ ) resulted in a connecting and irregular particles with an average particle size of approx. 80-100 nm. Thus, KCl:Sm (0.45 mol\%) shows better isolated and sub $100 \mathrm{~nm}$ particles of $\mathrm{KCl}: \mathrm{Sm}$ than that at other Sm concentration, which is considered as an optimum system for nano-based applications. This direct observation of the particle size was found to be consistent with the XRD data, confirming the nanoparticle grain size of $\mathrm{KCl}: \mathrm{Sm}$. Moreover, the presence of Sm in the $\mathrm{KCl}$ matrix was confirmed by EDS analysis [data not shown herein].

Fig. 3(a) shows the photoluminescence (PL) excitation spectra of pure $\mathrm{KCl}$ and $\mathrm{KCl}: \mathrm{Sm}(0.45 \mathrm{~mol} \%)$ in the UV-vis region at room temperature. The $\mathrm{PL}$ intensities of $\mathrm{KCl}$ and $\mathrm{KCl}: \mathrm{Sm}$, excited at the wavelength of 200-320 nm, were found in the comparable range. After the inclusion of $\mathrm{Sm}$ ion in $\mathrm{KCl}$, a peak at $265 \mathrm{~nm}$ was observed for pure $\mathrm{KCl}$, which was absent for KCl:Sm; however, a narrow peak at $257.2 \mathrm{~nm}$ and a broad peak in the range of 267-280 $\mathrm{nm}$ was observed for $\mathrm{KCl}: \mathrm{Sm}$. This phenomenon may be associated with the direct charge transfer (bound exciton), which indicates the presence of $\mathrm{Sm}^{3+}$ that is induced due to the photoreduction of $\mathrm{Sm}^{2+}$ to $\mathrm{Sm}^{3+} \cdot{ }^{\mathbf{1 6 , 2 1}}$ Size dispersion in KCl:Sm may lead to broadening of PL peak and being able to modify optical properties of luminescent centres, help to obtain higher PL intensities. Whereas, the observed red shift in the peak position (emergence of a new peak at $257.2 \mathrm{~nm}$ ) indicates the nano aspect, which is in well accordance with the TEM results. ${ }^{22}$

The PL emission spectrum of KCl (used in our study and shown in Fig. 3(b)) exhibits a small peak at $329 \mathrm{~nm}$ instead at $\sim 140 \mathrm{~nm}$ for pure $\mathrm{KCl}$ and it can be associated with the impurities already present in the used $\mathrm{KCl}^{23}$ After incorporating $\mathrm{Sm}$ in the $\mathrm{KCl}$ matrix, the resulting material $\mathrm{KCl}$ :Sm shows many other peaks at various positions in their emission spectra apart from the peak at $328 \mathrm{~nm}$. The PL emission spectrum of $\mathrm{KCl}: \mathrm{Sm}$ after excitation at the wavelength of $266 \mathrm{~nm}$ (corresponding to ${ }^{6} \mathrm{H}_{5 / 2} \rightarrow{ }^{4} \mathrm{I}_{9 / 2}$ transition) shows a series of emission peaks at the wavelength of 295-580 $\mathrm{nm}$. All these emission peaks resulting from the transitions of an electron from the energy level ${ }^{4} \mathrm{D}_{5 / 2}$ to various ground levels, such as ${ }^{6} \mathrm{H}_{5 / 2},{ }^{6} \mathrm{H}_{7 / 2},{ }^{6} \mathrm{H}_{9 / 2},{ }^{6} \mathrm{~F}_{5 / 2},{ }^{6} \mathrm{~F}_{7 / 2},{ }^{6} \mathrm{~F}_{9 /}$ ${ }_{2}$, and ${ }^{6} \mathrm{~F}_{11 / 2}$, were expected. ${ }^{24}$ At first instance, it appeared that the $\mathrm{Sm}$-doped $\mathrm{KCl}$ has created some more active defects at various positions inside the band gap of $\mathrm{KCl}$, which may work as trap centres for free hole/electron. This has been evidenced in ref. 25, where Sm deeply diffuses into the host lattice of $\mathrm{KCl}$ and causes significant changes in the band edge of the PL 


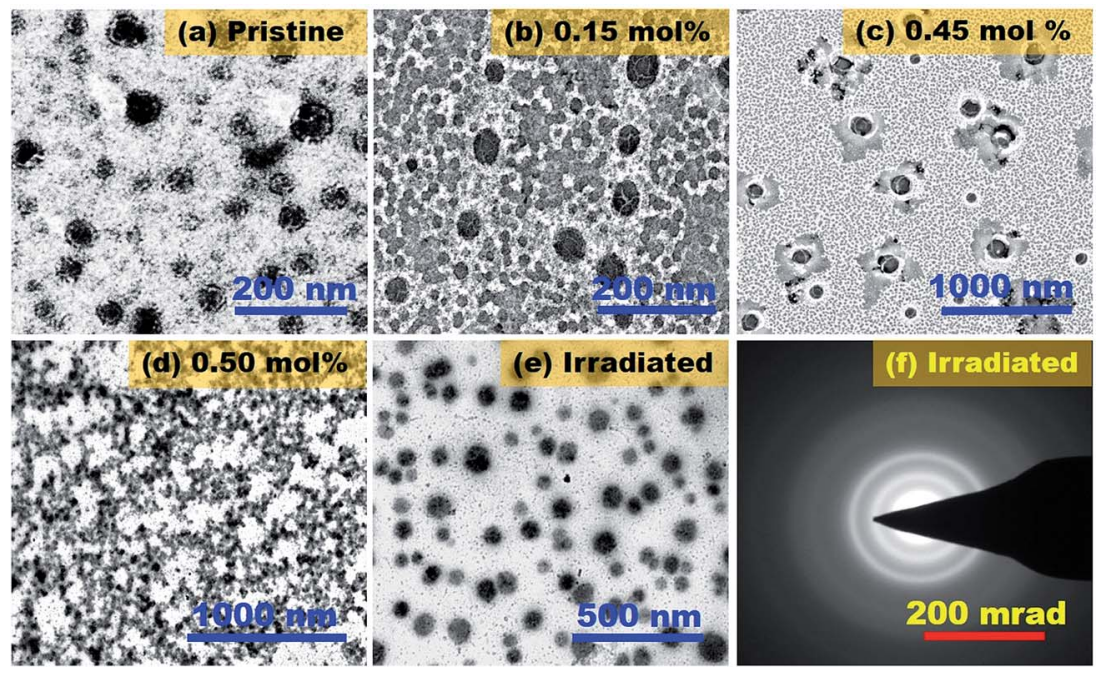

Fig. 2 TEM image of $\mathrm{KCl}$ powder (a) pristine $\mathrm{KCl}$, (b) $\mathrm{KCl}$ with $0.15 \mathrm{~mol} \%$ of Sm, (c) $0.45 \mathrm{~mol} \%$ of Sm, (d) $0.50 \mathrm{~mol} \%$ of Sm, (e) optimized Sm-doped $\mathrm{KCl}(0.45 \mathrm{~mol} \%)$ after irradiation with $500 \mathrm{~Gy}$ of gamma photons, and (f) SAD pattern of (e).

measurements. Based on the PL experimental data and available theoretical studies, ${ }^{\mathbf{2 4 , 2 6}}$ a proposed model of the energy band diagram for $\mathrm{KCl}: \mathrm{Sm}$ is schematically summarised in Fig. 3(c), where the above mentioned various transitions are shown in the energy level diagram.

For better understanding of our KCl:Sm surface elemental analysis, we employed XPS where the survey scan of $\mathrm{KCl}: \mathrm{Sm}$ shows the presence of peaks in XPS spectrum that were found to be associated with Sm-3d, Cl-2p [2 $\mathrm{p}_{1 / 2}$-at 198.7 and $2 \mathrm{p}_{3 / 2}$-at $198.9 \mathrm{eV}$ ], Cl-1s [at 284.6 eV], C-1s, O-1s, and K-2s [at $377.2 \mathrm{eV}$ ], as shown in Fig. 4(a). With the help of a deconvolution process, we examined the effects of the various elemental concentrations, as shown in Fig. 4(b) where the Sm-3d peak was deconvoluted. Deconvolution of the $\mathrm{Sm}-3 \mathrm{~d}$ spectrum was complex due to the presence of mixed oxidation states $\mathrm{Sm}^{3+}$ and $\mathrm{Sm}^{2+}$ as well as due to the multiple $3 \mathrm{~d}$-splitting on the nanoscale. The spinorbit doublet $\mathrm{Sm}^{3+} 3 \mathrm{~d}_{5 / 2,3 / 2}$ with the binding energy (BE) of 1083.7 and $1108.3 \mathrm{eV}$ and $\mathrm{Sm}^{2+} 3 \mathrm{~d}_{5 / 2,3 / 2}$ with the BE of 1081.1 and $1105.2 \mathrm{eV}$ can be clearly observed from the spectra and reveal the presence of both oxidation states of $\mathrm{Sm} .{ }^{27}$ Moreover, in the deconvolution process, we found additional peaks at $1074.8 \mathrm{eV}$ for $\mathrm{Sm}^{2+}$ and other broader peak at $1110.5 \mathrm{eV}$ in the Sm 3d XPS spectra, which can be assigned to the Sm Auger peak, ${ }^{28}$ which generally appears in the presence of metal oxide. In our study, we expected two types of metal bondings: (1) single metal bonding ( $\mathrm{Sm}-\mathrm{O}-\mathrm{Sm})$ and (2) mixed metal bonding ( $\mathrm{Sm}-$ $\mathrm{O}-\mathrm{K})$, where single metal bonding allow multiple oxidation states and mixed metal oxides prefer the formation of $\mathrm{Sm}^{3+} .^{29}$ This different types of metal bondings were further confirmed in the O-1s spectrum of $\mathrm{KCl}: \mathrm{Sm}$ nanophosphor, as shown in Fig. 5(c), where the peaks at $530.5 \mathrm{eV}$ and $526.7 \mathrm{eV}$ (after deconvolution) were found to be associated with $\mathrm{Sm}-\mathrm{O}-\mathrm{K}$ bond and $\mathrm{Sm}-\mathrm{O}-\mathrm{Sm}$ bond, respectively. ${ }^{30}$ The asymmetry in the $\mathrm{O}-1 \mathrm{~s}$ peak in Fig. 4(c) reveals $\mathrm{O}^{2-}$ ions association with all the compositional ions $\mathrm{K}^{+}, \mathrm{Cl}^{-}, \mathrm{Sm}^{2+}$, and $\mathrm{Sm}^{3+}$, which could be advantageous to the energy transfer mechanism. ${ }^{30}$

\subsection{OSL measurements}

The crystal structure, luminescent, and dosimetric properties of the material depend on the preparation methods. Fig. 5 shows the parametric curves of $\mathrm{KCl}$ and $\mathrm{KCl}: \mathrm{Sm}(0.45 \mathrm{~mol} \%)$ under various experimental parameters of the OSL system. Two stimulation sources of OSL, namely blue and green LEDs, for the fixed dose 0.1 Gy were used. Fig. 5(a) shows that the maximum intensity of the CW-OSL decay curves was obtained for a blue stimulation source, which is approximately two times higher than that of green light under the same experimental conditions. Another advantage of using blue light for stimulation lies in its large photoionization cross-section, ${ }^{31}$ which is reflected in the rapid decay of the CW-OSL signal. Therefore, we chose blue light for further OSL studies. Fig. 5(b) shows the CW-OSL decay curve as a function of $\mathrm{Sm}$ concentration at the fixed dose of $1 \mathrm{~Gy}$ of gamma rays. The maximum intensity of the KCl:Sm nanophosphor was found at $0.45 \mathrm{~mol} \%$ at the optimal annealing temperature of $710{ }^{\circ} \mathrm{C}$. Moreover, the intensity increased with the increasing $\mathrm{Sm}$ concentration from 0.15 to $0.45 \mathrm{~mol} \%$ followed by a decrease at higher dopant concentrations $(0.50$ mol\%) [Fig. 5(c)]. This behaviour could be due to either thermal quenching or conglomeration of particles at a higher concentration of Sm, resulting in saturation of luminescence/ recombination centres. ${ }^{3 a}$ We found that its CW-OSL signal was very intense at $9 \times 10^{6}$ compared to that of other lanthanides such as KCl:Dy and KCl:Tb (both at $0.45 \mathrm{~mol} \%$ ) synthesised in our lab, which showed a CW-OSL intensity of $2.85 \times$ $10^{5}$ and $2.5 \times 10^{5}$, respectively. Thus, the observed behaviour of the OSL intensity as a function of Sm concentration reveals the optimised concentration of $0.45 \mathrm{~mol} \%$. In connection with the material structural properties, this optimised percentage of Sm can be associated with the particle size of $\mathrm{KCl}$ systems, which have been observed as well-isolated nanoparticle of $\mathrm{KCl}: \mathrm{Sm}$ [Fig. 2(c)]. In the same line, the reduction in the OSL intensity for $\mathrm{KCl}: \mathrm{Sm}(0.50 \mathrm{~mol} \%)$ could be associated with the observed 

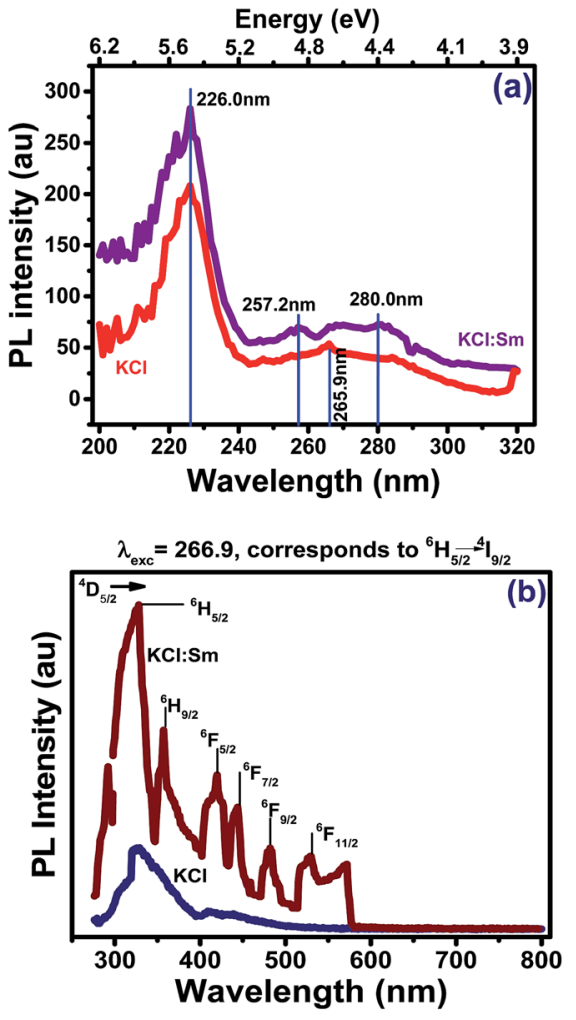

(c) Energy level diagram of $\mathrm{Sm}^{3+}$

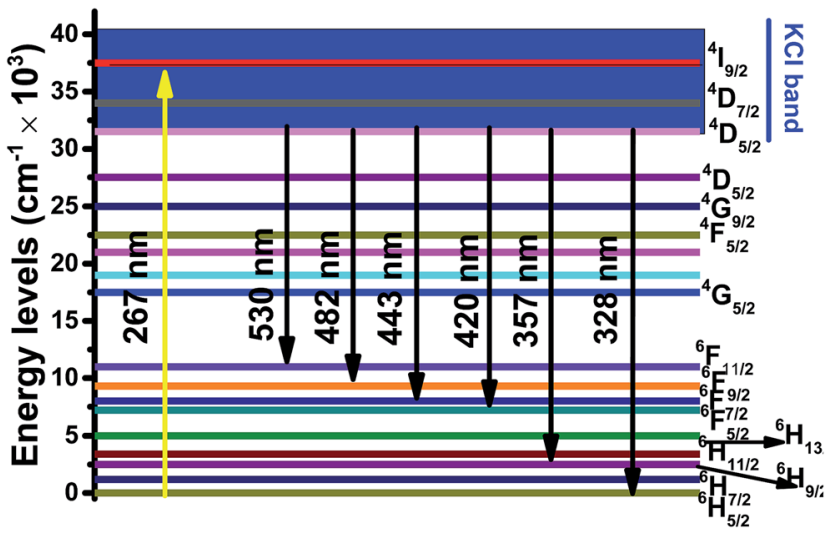

Fig. $3 \mathrm{PL}$ (a) excitation and (b) emission spectra of $\mathrm{KCl} \& \mathrm{KCl}: \mathrm{Sm}$ (optimised dopant conc. of $0.45 \mathrm{~mol} \%$ ) and (c) schematic energy level diagram of $\mathrm{Sm}^{3+}$ in the $\mathrm{KCl}$ host matrix.

agglomeration of particles found at $0.50 \mathrm{~mol} \% \mathrm{Sm}$ in Fig. 2(d). ${ }^{6 a}$ Therefore, this study excludes the possibility of thermal quenching, which is also capable of bringing a reduction in the OSL intensity. Further, TEM studies suggested that the percentage of $\mathrm{Sm}$ in $\mathrm{KCl}$ could affect the particle size of $\mathrm{KCl}$ on the nanoscale. To investigate the irradiation-induced change on the shape and size of the particle, a 500 Gy gamma photoninduced KCl:Sm (0.45 mol\%) was investigated by TEM, as shown in Fig. 2(e). From Fig. 2(e), we found that the radiation brings a drastic change in the particle size but maintains the shape (spherical) and homogeneity. It shows a large density of particle size in the range of $20-50 \mathrm{~nm}$ (sub $50 \mathrm{~nm}$ ) homogeneously distributed between the other particle size range 90-
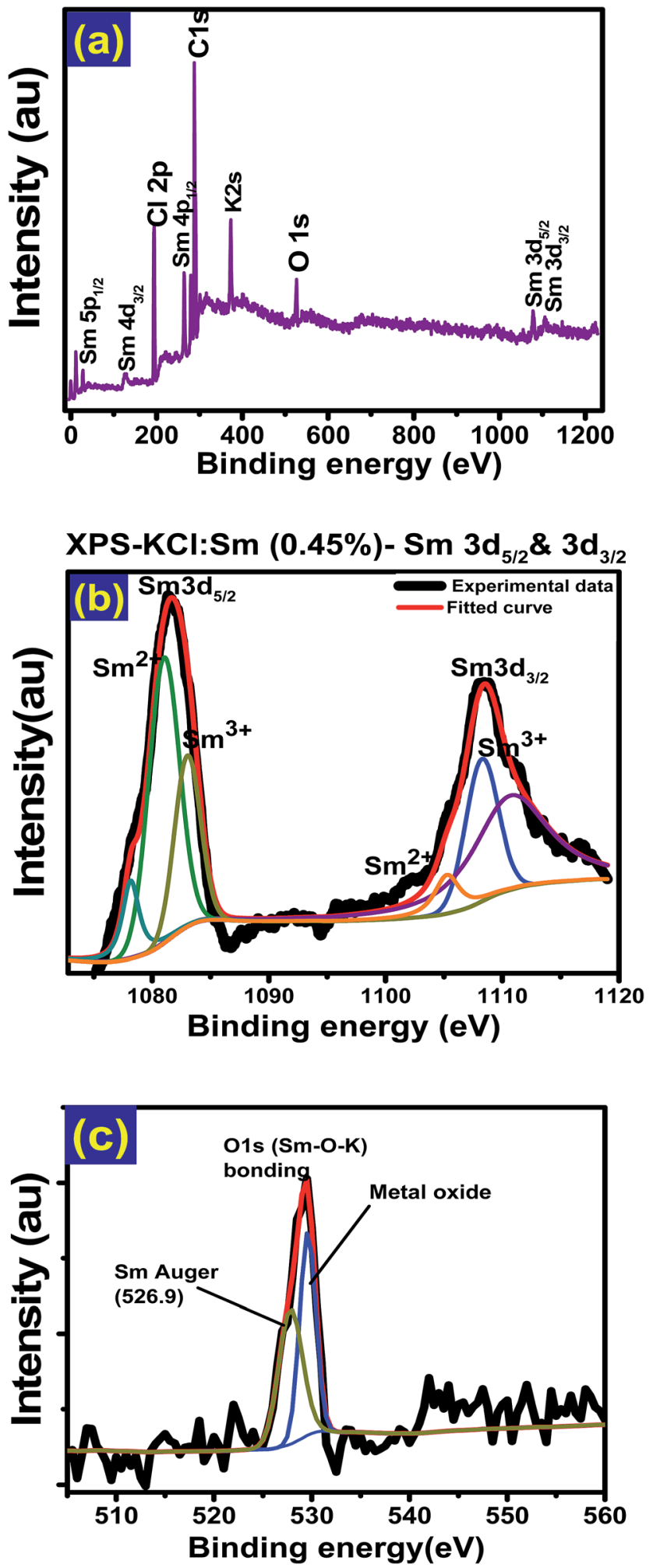

Fig. 4 XPS spectra of $\mathrm{KCl}: \mathrm{Sm}(0.45 \mathrm{~mol} \%)$ (a) survey scan, (b) deconvolution-to $3 d_{3 / 2}$ and $3 d_{5 / 2}$ and (c) to $\mathrm{O}-1$ s of $\mathrm{KCl}: \mathrm{Sm}$.

$180 \mathrm{~nm}$. Thus, irradiation was found to be an assistive process to grow particles at one site at the cost of another site. Irradiation-induced annealing is capable of changing the crystalline nature and may lead to a change in sensitivity, as shown 


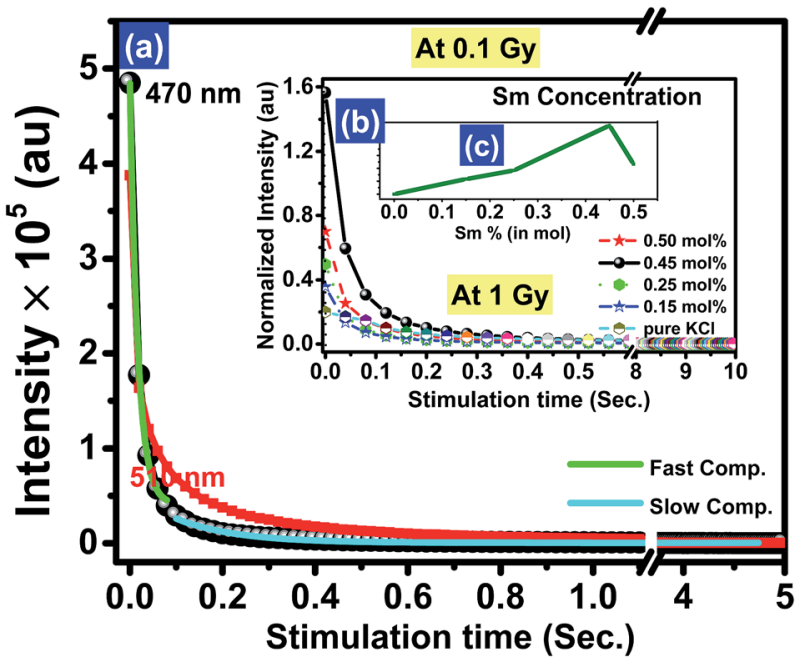

Fig. 5 Parametric curves: CW-OSL decay curves of $\mathrm{KCl}: \mathrm{Sm}$ after irradiation from $\mathrm{Cs}^{137}$-sourced gamma ray for 0.1 Gy of $0.45 \mathrm{~mol} \% \mathrm{Sm}$ dopant at two different OSL simulation wavelength (1) blue light: $470 \mathrm{~nm}$ (black sphere) and (2) green light: $510 \mathrm{~nm}$ (red square), (b) different dopant concentration of $\operatorname{Sm}(0.15,0.25,0.45, \& 0.50 \mathrm{~mol} \%)$ along with pristine $\mathrm{KCl}$ at blue OSL stimulation light for $1 \mathrm{~Gy}$, and (c) plot of the obtained maximum intensity from plot (b) as a function of Sm concentration. Further OSL curve of $\mathrm{KCl}: \mathrm{Sm}(0.45 \%)$ at $0.1 \mathrm{~Gy}$ dose has been fitted with exponentially decay in two component (1) fast and (2) slow shown in (a) corresponding to blue light stimulation.

in Fig. 2(f) [a SAD pattern of Fig. 2(e)]. Various ring patterns in the SAD image (as observed in Fig. 1) shows the polycrystalline nature of gamma-irradiated samples and further reveals that the polycrystalline nature of non-irradiated $\mathrm{KCl}: \mathrm{Sm}$ remains unchanged at high doses. Thus, the divulge homogeneous, regular, and sub-50 $\mathrm{nm}$ polycrystalline particles were found to bring significant improvement in the photoluminescence properties of the investigated phosphor. ${ }^{32}$

To calculate the decay rate, the CW-OSL decay curve was fitted with two components (minimum) for the best fit, where the first component describes the steeper part while the second component explains the less steep part of the observed CW-OSL decay curve. These are also known as a fast and slow component. This decay rate was obtained from Fig. 5 by fitting eqn (2) and (3). The CW-OSL decay curve stimulated by the blue LED light can be shown from the following equations:

$$
I_{\text {OSL (blue })}=A_{1} \mathrm{e}^{-x / \tau_{1}}+I_{01}
$$

where $I_{01}=40936.43923, A_{1}=443269.09834, \tau_{1}=0.01744$, [for the fast component]

$$
I_{\mathrm{OSL}(\text { blue })}=A_{2} \mathrm{e}^{-x / \tau_{2}}+I_{02}
$$

where $I_{02}=367.14957, A_{2}=55482.60896, \tau_{2}=0.13011$, [for the slow component].

With these values of decay constants, the photoionization cross-section $(\sigma)$ was calculated as follows: ${ }^{33}$

$$
\sigma=\frac{1}{j} \times \tau
$$

where the photon flux $(j)$ and decay constant $(\tau)$ are required for calculating $\sigma$ and $j$ depend on the wavelength and intensity of the stimulation light used. $\sigma$ was calculated to be $0.42 \times$ $10^{-15} \mathrm{~cm}^{2}$ and $0.32 \times 10^{-16} \mathrm{~cm}^{2}$ for fast and slow components, respectively, at the blue wavelength value $(470 \mathrm{~nm})$ and intensity of $80 \mathrm{~mW} \mathrm{~cm}^{-2}$. This more than 10 times difference in $\sigma$ value at the fast and slow part of CW-OSL is one of the factors to bring the difference in their respective CW-OSL intensities. Therefore, it can be concluded that for the higher value of $\sigma$, a high number of electrons are released from defects, leading to a recombination process and contributing to the intensity. However, these calculated and experimental data do not indicate the nature of the defect centres that are responsible for the OSL processes. ${ }^{10}$ However, PL analysis has improved the understanding of the defect centres in $\mathrm{KCl}: \mathrm{Sm}$, where we analysed the presence of many energy levels within the forbidden band gap of $\mathrm{KCl}$. Thus, the observed luminescence effect occurs due to an excess of defects centres such as anion vacancies called F-centres. ${ }^{34}$

To investigate the dose response of the optimised phosphor $\mathrm{KCl}: \mathrm{Sm}(0.45 \mathrm{~mol} \%)$, the samples were irradiated with various doses of gamma photons $\left({ }^{137} \mathrm{Cs}\right.$ source in the dose ranges from $100 \mathrm{mGy}$ to $1 \mathrm{kGy})$ and beta source $\left({ }^{90} \mathrm{Sr} /{ }^{90} \mathrm{Y}\right.$ in the doses from 3 mGy to 5 Gy). The corresponding CW-OSL curves are shown in Fig. 6(a) and (b) for gamma and beta irradiation, respectively. The shape and decay rate of gamma and beta-irradiated OSL curves are slightly different and probably show their different ways of interaction [Fig. 6(a) and (b)]. The OSL intensity increased with the increasing gamma irradiation in the dose range from $10 \mathrm{cGy}$ to $500 \mathrm{~Gy}$ and then decreased with dose beyond 500 Gy [Fig. 6(c)]. The observed saturation in intensity at high doses depicted in Fig. 6(c) could be due to the saturation of luminescence or reduction in the recombination centres. ${ }^{35}$ In this analysis, a linear fit in the dose range up to 500 Gy revealed a linear correlation coefficient $(r=0.978)$. Fig. 6(d) indicates that the $\mathrm{KCl}: \mathrm{Sm}$ nanophosphor may be a good sensitive material for radiation dosimetry. ${ }^{13}$ The dose response for beta irradiation also yielded a linear correlation coefficient $r=0.91$ for doses up to 3 Gy [Fig. 6(b)]. The OSL signal was found to be linear in the dose range of $100 \mathrm{mGy}$ to $750 \mathrm{~Gy}$, and after this range, the signal started to saturate. The minimum detectable dose (MDD) of the prepared phosphor was estimated to be $\sim 6.8$ $\mu \mathrm{Gy}$ using the standard method. ${ }^{36}$

A comparison of the experimental OSL phosphor $\mathrm{KCl}: \mathrm{Sm}$ with the commercially available OSL material $\alpha-\mathrm{Al}_{2} \mathrm{O}_{3}: \mathrm{C}$ and $\mathrm{BeO}$ was carried out, as shown in Fig. 7. The intensity of $\mathrm{KCl}: \mathrm{Sm}$ is around one-third of that of $\mathrm{Al}_{2} \mathrm{O}_{3}: \mathrm{C}$ and $\mathrm{BeO}$ at the fixed dose of $1 \mathrm{~Gy}$ of ${ }^{137} \mathrm{Cs}$ gamma photons. Although fading is one of the important characteristics of dosimetry that can be affected by the dopant concentration, the type of dopant, and energy of ionising radiation, ${ }^{5}$ we depicted fading of $\mathrm{KCl}: \mathrm{Sm}$ nanophosphor at one test dose of 0.5 Gy of gamma photons (Fig. 8). For the same fading issue, the samples were stored in the dark at room temperature after irradiation for a period of 50 days and the CW-OSL decay response curve was obtained at a certain gap of time (in days), as shown in Fig. 8(b). For clarity, only three curves are shown: just after the irradiation, 5 days after 

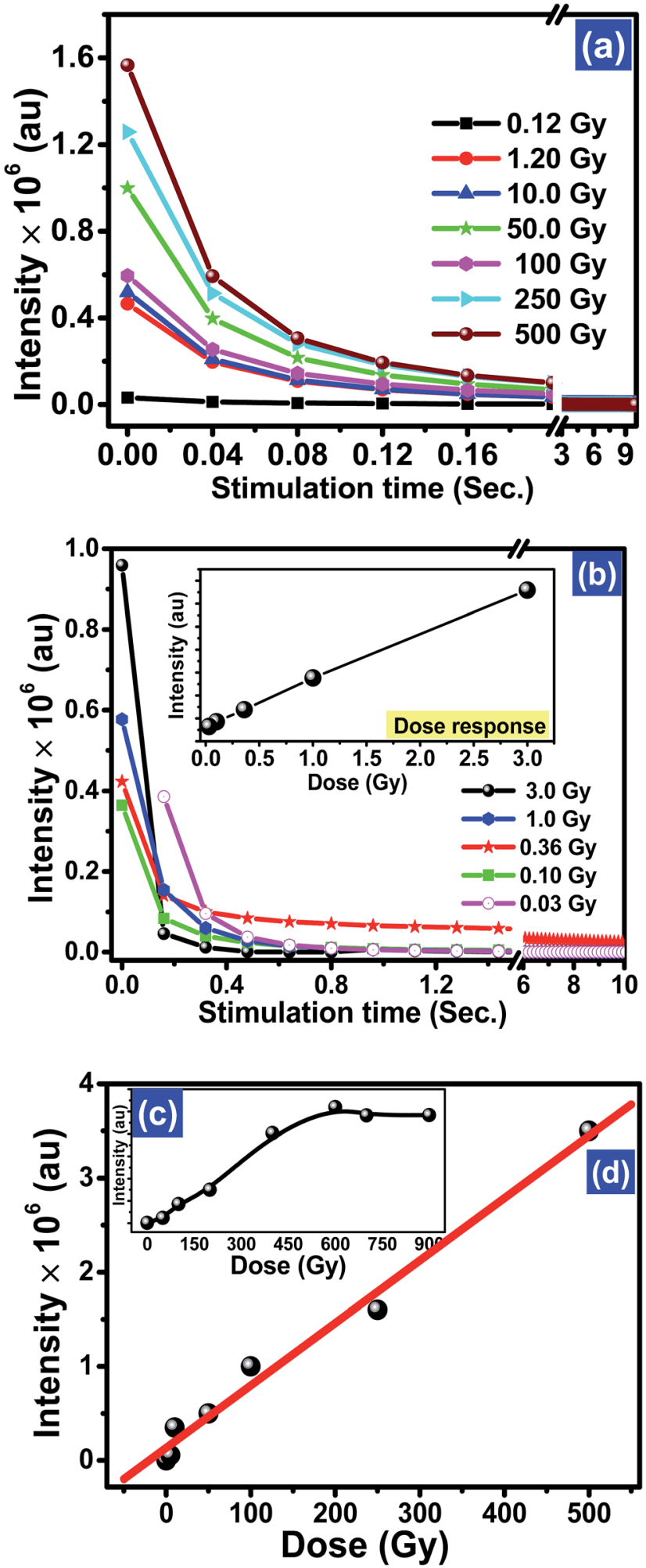

Fig. 6 CW-OSL decay curves of $\mathrm{KCl}: \mathrm{Sm}(0.45 \mathrm{~mol} \%)$ irradiated from (a) $\mathrm{Cs}^{137}$-sourced gamma photons at different doses, (b) ${ }^{90} \mathrm{Sr} /{ }^{90} \mathrm{Yr}$ sourced $\beta$-rays at different doses in the range of 0.03-3 Gy, linset shows the dose response of (b)], (c) dose response of (a) in the dose range of 0.12-1000 Gy, and (d) zoomed linear part of (c).

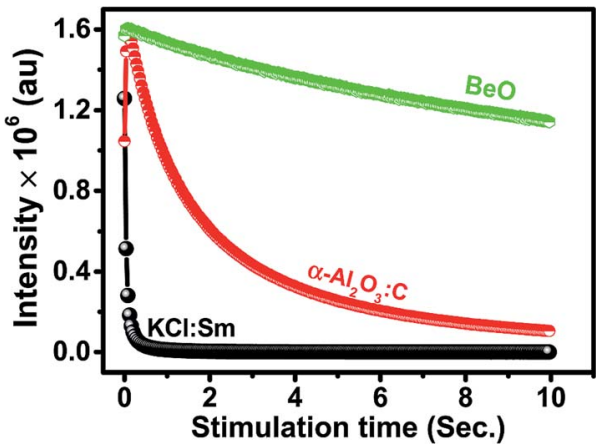

Fig. $7 \mathrm{CW}$-OSL comparison curves of $\mathrm{KCl}: \mathrm{Sm}$ with commercially available $\mathrm{Al}_{2} \mathrm{O}_{3}: \mathrm{C}$ (Landauer Inc., USA) and $\mathrm{BeO}$ (Thermalox® ${ }^{\circledR} 95$, Materiaon Inc., USA) irradiated at 1 Gy of gamma photons $\left({ }^{137} \mathrm{Cs}\right)$.

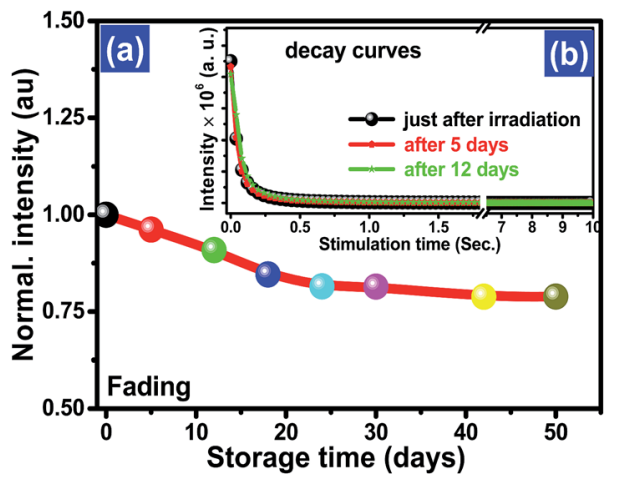

Fig. 8 The fading curve of $\mathrm{KCl}: \mathrm{Sm}(0.45 \mathrm{~mol} \%)$ (a) up to test 50 days and (b) CW-OSL curve as a function of storage days up to 12 days [higher days not shown to maintain clarity].

irradiation, and 12 days after irradiation. A nominal reduction of $7-8 \%$ in normalised intensity was found for the first 12 days after irradiation [Fig. 8(a)], which may be due to the presence of shallow traps. A $20 \%$ decrease in the intensity was observed in 50 days after irradiation [Fig. 8(a)]. The nominal fading of 7-8\% in 12 days in our OSL phosphor KCl:Sm indicates that it may be used in patient radiation dosimetry in radiotherapy and radiology. Reusability is the important property of a dosimetric material that indicates its efficiency over repeated use (irradiation-reading-bleaching cycle). The CW-OSL decay curve of gamma-irradiated KCl:Sm nanophosphors with the test dose of 0.5 Gy was obtained followed by in situ bleaching for 20 minutes to quench all electrons in the defect centres. This was again irradiated with the same dose of 0.5 Gy and its CW-OSL intensity was obtained. This was repeated and this read-out cycle was performed at least 7-8 times at the same sample with keeping the test dose at 0.5 Gy. Fig. 9(a) shows the variation of about 6$7 \%$ in the signal over repeated use. This study demonstrates that the KCl:Sm nanophosphor also possesses good reusability. For practical applications, dosimetric materials should also have the property of reproducibility. $\mathrm{KCl}: \mathrm{Sm}$ was synthesised three times terming them batch each time. Eight-nine aliquots of $\mathrm{KCl}: \mathrm{Sm}$ powder $(8 \mathrm{mg}$ ) from all three batches were exposed to the test dose of 0.5 Gy. The CW-OSL signals were obtained for 


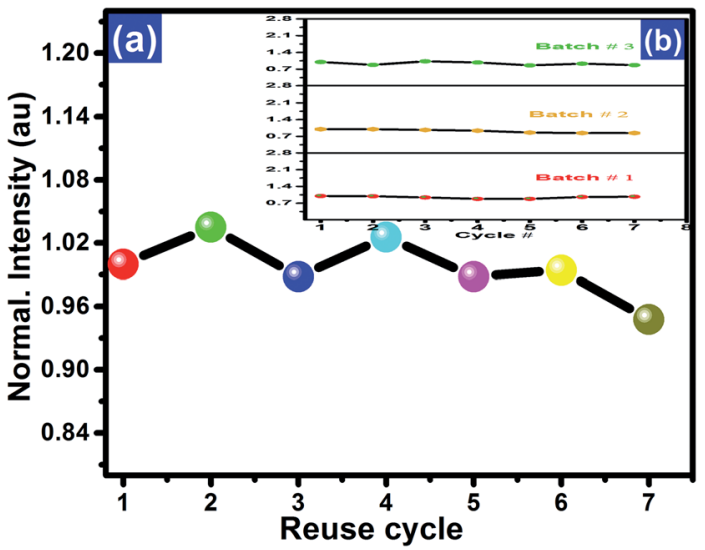

Fig. 9 (a) Reusability of $\mathrm{KCl}: \mathrm{Sm}(0.45 \mathrm{~mol} \%)$ that is irradiated with 0.5 Gy from gamma-sourced ${ }^{137} \mathrm{Cs}$ and (b) reproducibility with different batches of $\mathrm{KCl}: \mathrm{Sm}(0.45 \mathrm{~mol} \%)$ under the test dose of $0.5 \mathrm{~Gy}$.

10 seconds. The OSL reading of irradiated KCl:Sm nanophosphor was found to be reproducible [Fig. 9(b)] with the observed variation of $4-5 \%$ across the batches.

Then, in the light of our both performed experimental analysis (1) structural and (2) OSL, we presented a model (depicted in Fig. 10) to understand the possible mechanism of the OSL properties of $\mathrm{KCl}: \mathrm{Sm}$. We understood the full OSL mechanism in three parts: part (1) excitation, (2) capture process, and (3) recombination process, which comes in sequences one after another. The unirradiated sample whose absorbed dose measurement is our aim, is brought subjected to excitation process by allowing energetic irradiation. As a result, photoionization takes place, in which the valence band (VB) electron of $\mathrm{KCl}$ moves into the conduction band (CB) of $\mathrm{KCl}$, and generates the delocalized/free charge carriers $\left(\mathrm{e}^{-}\right.$and $\left.\mathrm{h}^{+}\right)$in the $\mathrm{VB}$ and $\mathrm{CB}$, respectively. Some of the energy levels of $\mathrm{Sm}^{3+}$ may exist within the both the bands (VB and $\mathrm{CB}$ ) of $\mathrm{KCl}$. The energy levels that lie within the VB release an electron to the VB of $\mathrm{KCl}$ and behave like a hole defect centre. At the same time, the $\mathrm{Sm}^{3+}$ energy levels inside the $\mathrm{CB}$ can capture the free $\mathrm{e}^{-}$ from the $\mathrm{CB}$ and make a bound state of $\mathrm{e}^{-}$and $\mathrm{h}^{+}$within $\mathrm{Sm}^{3+}$ energy levels, which is known as an exciton. After this excitation

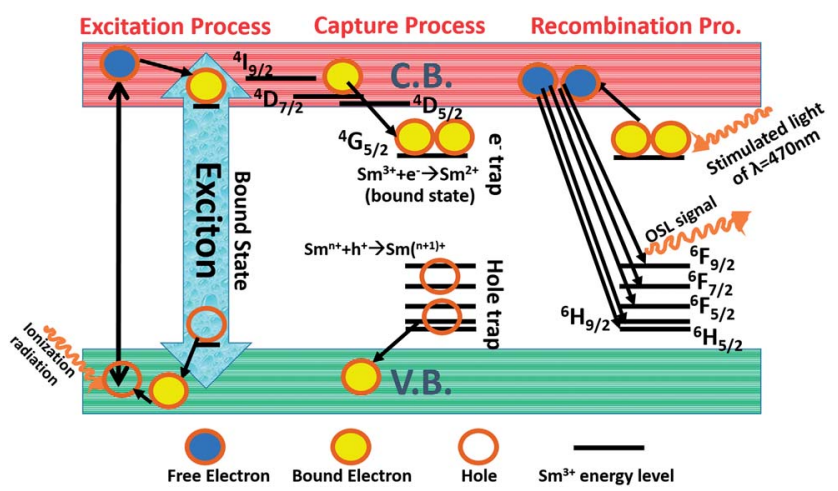

Fig. 10 A simple model for OSL mechanism: a schematic of nanophosphor $\mathrm{KCl}: \mathrm{Sm}$ OSL processes. process, the capture process starts where the energy level at nearest below the $\mathrm{CB}$ receives some $\mathrm{e}^{-}$via a non-radiative process, which is known as electron trapping and occur through the following process: ${ }^{37}$

$$
\mathrm{Sm}^{3+}+\mathrm{e}^{-} \text {(free electron capturing) } \rightarrow \mathrm{Sm}^{2+} \text { (bound state). }
$$

The $\mathrm{Sm}^{3+}$ energy levels at nearest above the VB release an $\mathrm{e}^{-}$ to $\mathrm{VB}$, which work as hole centres through a process known as hole trapping that occurs through the following process: ${ }^{38}$

$$
\mathrm{Sm}^{n}+\mathrm{h}^{+} \rightarrow \mathrm{Sm}^{n+1} \text {. }
$$

This capturing process contributes to obtaining a stronger OSL signal, where the capturing process increases with the introduction of a larger number of energy levels near both the bands. The same was achieved in this case by doping $\mathrm{Sm}$ ions into the nano $\mathrm{KCl}$ matrix. This has been confirmed in our PL studies. In the last process, namely recombination process, this nanophosphor was brought to optical stimulation, where light of wavelength $470 \mathrm{~nm}$, also known as stimulation light source, released the trapped electron from the $\mathrm{e}^{-}$trap centres to free the $\mathrm{e}^{-}$in the CB. These free $\mathrm{e}^{-}$will undergo a transition from the CB to various $\mathrm{Sm}^{3+}$ hole trap centres and release the OSL signal through the following process: ${ }^{39}$

$$
\left.\left(\mathrm{Sm}^{n+}+\mathrm{h}^{+}\right)+\mathrm{e}^{-} \rightarrow \mathrm{Sm}^{n+}+h \nu \text { (light emission at } 420 \mathrm{~nm}\right)
$$

This emission spectrum of KCl:Sm shows the transition in the range from 330 to $580 \mathrm{~nm}$, mainly due to the $\mathrm{Sm}^{3+}$ oxidation state.

\section{Conclusion}

In this synthesis process, we successfully established an easy process through which we overcame the barrier of dopant agglomeration in the host lattice using a certain dopant concentration ( $0.45 \mathrm{~mol} \%$ ) and we came close to developing the nanophosphor materials for dosimetric applications. Moreover, according to our comprehensive OSL studies, properties such as dynamic linear dose response, low fading, high reproducibility, and reusability, which endorse our synthesis materials for OSL applications, show good sensitivity up to $80 \%$ compared to those of commercial OSL compounds. This first ever report [to the best of our knowledge] on $\mathrm{KCl}: \mathrm{Sm}^{3+}(0.45 \mathrm{~mol} \%)$ nanophosphor, we have found well isolated polycrystalline nanophosphor KCl:Sm in the mixed oxidation state of $\mathrm{Sm}^{3+}$. Herein, $\mathrm{Sm}^{3+}$ works as an important dopant to increase the OSL signal by introducing various energy levels within the band gap of $\mathrm{KCl}$ and near to VB and CB, which further improves the $\mathrm{e}^{-}$and $\mathrm{h}^{+}$ capturing process. Based on the above mentioned facts, the proposed model enlightens the OSL behaviour of $\mathrm{KCl}: \mathrm{Sm}^{3+}$ material. Thus, overall, this study opens a new approach for 2D medical imaging and high radiation dosimetry. In future, this phosphor may be used in space dosimetry and real-time dosimetry. 


\section{Acknowledgements}

The research was fully supported by AIIMS (All India Institute of Medical Research) fellowship. MSG are grateful to Mr D. Sen and Mr Birendra, Health Physics Lab, IUAC New Delhi for support in the preparation of samples. Authors acknowledge the Department of Science and Technology (DST) for supporting AIIMS and IUAC with the characterizations tools HRTEM and EDS-SEM, respectively.

\section{References}

1 A. Viamonte, L. A. R. Da Rosa, L. A. Buckley, A. Cherpak and J. E. Cygler, Radiotherapy dosimetry using a commercial OSL system, Med. Phys., 2008, 35(4), 1261-1266.

2 M. S. Akselrod, N. A. Larsen, V. Whitley and S. W. S. McKeever, Thermal quenching of F-centre luminescence in $\mathrm{Al}_{2} \mathrm{O}_{3}: \mathrm{C}$, Radiat. Prot. Dosim., 1999, 84(1-4), 39-42.

3 (a) E. G. Yukihara and S. W. S. McKeever, Optically stimulated luminescence: fundamentals and applications, John Wiley \& Sons, 2011; (b) J. C. Polf, A study of optically stimulated luminescence in $\mathrm{Al}_{2} \mathrm{O}_{3}$ fibres for the development of a realtime, fibre optic dosimetry system, PhD Thesis, Oklahoma State University, 2002.

4 K.-H. Lee and J. H. Crawford Jr, Luminescence of the F centre in sapphire, Phys. Rev. B: Condens. Matter Mater. Phys., 1979, 19(6), 3217.

5 A. S. Pradhan, J. I. Lee and J. L. Kim, Recent developments of optically stimulated luminescence materials and techniques for radiation dosimetry and clinical applications, J. Med. Phys., 2008, 33(3), 85.

6 (a) B.-I. Lee, E.-s. Lee and S.-H. Byeon, Assembly of Layered Rare-Earth Hydroxide Nanosheets and $\mathrm{SiO}_{2}$ Nanoparticles to Fabricate Multifunctional Transparent Films Capable of Combinatorial Color Generation, Adv. Funct. Mater., 2012, 22(17), 3562-3569; (b) H. He, X. Zhang and G. Li, Synthesis and properties study of new rare earth sodium borates $\mathrm{Eu}^{3+}$-doped $\mathrm{Na}_{3} \mathrm{Y}\left(\mathrm{BO}_{3}\right)_{2}$, Micro Nano Lett., 2012, 7(3), 228231.

7 L. C. Yong, H. Wagiran and A. K. Ismail, Thermoluminescence Performance of Carbon-doped Aluminium Oxide for Dose Measurement by Various Preparation Methods, J. Technol., 2013, 62(3), 2013.

8 K. P. Muthe, M. S. Kulkarni, N. S. Rawat, D. R. Mishra, B. C. Bhatt, A. Singh and S. K. Gupta, Melt processing of alumina in graphite ambient for dosimetric applications, $J$. Lumin., 2008, 128(3), 445-450.

9 A. Twardak, P. Bilski, B. Marczewska, J. I. Lee, J.-L. Kim, W. Gieszczyk, A. Mrozik, M. Sądel and D. Wróbel, Properties of lithium aluminate for application as an OSL dosimeter, Radiat. Phys. Chem., 2014, 104, 76-79.

10 A. Twardak, P. Bilski, B. Marczewska and W. Gieszczyk, Analysis of TL and OSL kinetics of lithium aluminate, Radiat. Meas., 2014, 71, 143-147.

11 Y. Zheng, Z. Han, J. P. Driewer, D. A. Low and H. H. Li, Theoretical and empirical investigations of $\mathrm{KCl}: \mathrm{Eu}^{2+}$ for nearly water-equivalent radiotherapy dosimetry, Med. Phys., 2010, 37(1), 146.

12 Z. Han, J. P. Driewer, Y. Zheng, D. A. Low and H. H. Li, Quantitative megavoltage radiation therapy dosimetry using the storage phosphor $\mathrm{KCl}: \mathrm{Eu}^{2+}$, Med. Phys., 2009, 36(8), 3748-3757.

13 H. H. Li, J. P. Driewer, Z. Han, D. A. Low, D. Yang and Z. Xiao, Two-dimensional high-spatial-resolution dosimeter using europium doped potassium chloride: a feasibility study, Phys. Med. Biol., 2014, 59(8), 1899.

14 Y. Douguchi, H. Nanto, T. Sato, A. Imai, S. Nasu, E. Kusano and A. Kinbara, Optically stimulated luminescence in Eudoped KBr phosphor ceramics, Radiat. Prot. Dosim., 1999, 84(1-4), 143-147.

15 (a) E. Snitzer, Optical maser action of $\mathrm{Nd}^{3+}$ in a barium crown glass, Phys. Rev. Lett., 1961, 7(12), 444; (b) J. Qiu, K. Miura, K. Nouchi, T. Suzuki, Y. Kondo, T. Mitsuyu and K. Hirao, Valence manipulation by lasers of samarium ion in micrometer-scale dimensions inside the transparent glass, Solid State Commun., 1999, 113(6), 341-344; (c) R. Nomura, T. Matsuno and T. Endo, Samarium IodideCatalyzed Pinacol Coupling of Carbonyl Compounds, J. Am. Chem. Soc., 1996, 118(46), 11666-11667.

16 M. Kusaba, N. Nakashima, W. Kawamura, Y. Izawa and C. Yamanaka, The Higher yield of photoreduction from $\mathrm{Eu}^{3+}$ to $\mathrm{Eu}^{2+}$ with shorter wavelength irradiation, Chem. Phys. Lett., 1992, 197(1), 136-140.

17 H. H. Li, Z. Xiao, R. Hansel, N. Knutson and D. Yang, Performance of $\mathrm{KCl}: \mathrm{Eu}^{2+}$ storage phosphor dosimeters for low-dose measurements, Phys. Med. Biol., 2013, 58(12), 4357.

18 P. D. Sahare, M. Singh and P. Kumar, A new high sensitivity $\mathrm{Na}_{2} \mathrm{LiPO}_{4}$ :Eu OSL phosphor, RSC Adv., 2015, 5(5), 3474-3481.

19 Manual for the guide to RISO TL/OSL reader, DTU, Denmark, 2013.

20 T. N. Blanton, T. C. Huang, H. Toraya, C. R. Hubbard, S. B. Robie, D. Louër, H. E. Göbel, G. Will, R. Gilles and T. Raftery, JCPDS-International Centre for Diffraction Data round robin study of silver behenate. A possible lowangle X-ray diffraction calibration standard, Powder Diffr., 1995, 10(02), 91-95.

21 P. Bamfield and M. G. Hutchings, Chapter 4 Phenomena Involving Absorption of Light and Energy Transfer, in Chromic Phenomena: Technological Applications of Colour Chemistry (2), The Royal Society of Chemistry, 2010, pp. 366-470.

22 N. Saxena, P. Kumar, D. Kabiraj and D. Kanjilal, Optostructural studies of well-dispersed silicon nanocrystals grown by atom beam sputtering, Nanoscale Res. Lett., 2012, $7(1), 547$.

$23 \mathrm{~K}$. Teegarden and G. Baldini, Optical absorption spectra of the alkali halides at $10 \mathrm{~K}$, Phys. Rev., 1967, 155(3), 896.

24 Q. Wu, H. Li, W. Xia, X. Fu, Z. Fu, S. Zhou, S. Zhang and J. H. Jeong, Investigation of the Structure and Photoluminescence Properties of $\mathrm{Ln}^{3+}\left(\mathrm{Eu}^{3+}, \mathrm{Dy}^{3+}, \mathrm{Sm}^{3+}\right)$ Ion-Doped $\mathrm{NaY}(\mathrm{MoO} 4)_{2}$, J. Electrochem. Soc., 2011, 158(12), J387-J393. 
25 Y. Harada and S. Hashimoto, Enhancement of band-edge photoluminescence of bulk $\mathrm{ZnO}$ single crystals coated with alkali halide, Phys. Rev. B: Condens. Matter Mater. Phys., 2003, 68(4), 045421.

26 C. K. Jayasankar and P. Babu, Optical properties of $\mathrm{Sm}^{3+}$ ions in lithium borate and lithium fluoroborate glasses, J. Alloys Compd., 2000, 307(1-2), 82-95.

27 (a) J. C. Polf, A study of optically stimulated luminescence in $\mathrm{Al}_{2} \mathrm{O}_{3}$ fibres for the development of a real-time, fibre optic dosimetry system, 2002; (b) B. V. Crist, Handbook of Monochromatic XPS spectra, XPS international, 1999; (c) G. K. Hodgson, S. Impellizzeri, G. L. Hallett-Tapley and J. C. Scaiano, Photochemical synthesis and characterization of novel samarium oxide nanoparticles: toward a heterogeneous Brønsted acid catalyst, RSC Adv., 2015, 5(5), 3728-3732.

28 V. Kuncser and L. Miu, Surface Reactivity and Magnetism at Metal-Semiconductor Interfaces, in Size Effects in Nanostructures: Basics and Applications, ed. V. Kuncser and L. Miu, Springer, 2014, vol. 205.

29 T.-D. Nguyen, D. Mrabet and T.-O. Do, Controlled selfassembly of $\mathrm{Sm}_{2} \mathrm{O}_{3}$ nanoparticles into nanorods: simple and large scale synthesis using bulk $\mathrm{Sm}_{2} \mathrm{O}_{3}$ powders, $J$. Phys. Chem. C, 2008, 112(39), 15226-15235.

30 C. D. Wanger, W. M. Riggs, L. E. Davis, J. F. Moulder and G. E. Muilenberg, Handbook of X-ray Photoelectron Spectroscopy, Perkin-Elmer Corporation: Physical Electronics Division, Waltham, M.A., 1979.

31 R. A. Barve, R. R. Patil, S. V. Moharil, N. P. Gaikwad, B. C. Bhatt, R. Pradeep, D. R. Mishra and M. S. Kulkarni, $\mathrm{Na}_{2} \mathrm{SiF}_{6}: \mathrm{Cu}, \mathrm{P}$ : a new OSL phosphor for the radiation dosimetric applications, Radiat. Prot. Dosim., 2015, 163(4), 439-445.

32 (a) A. Lakshmanan, Sintering of ceramics: new emerging techniques, InTech, Rijeka, 2012, p. 324; (b) D. R. Baer, D. J. Gaspar, P. Nachimuthu, S. D. Techane and D. G. Castner, Application of surface chemical analysis tools for characterization of nanoparticles, Anal. Bioanal. Chem., 2010, 396(3), 983-1002.

33 J. H. Choi, G. A. T. Duller and A. G. Wintle, Analysis of quartz LM-OSL curves, Ancient TL, 2006, 24(1), 9-20.

34 N. F. Mott and R. W. Gurney, Electronic Theories in Ionic Solids, Oxford Univ. Press, New York, 1940.

$35 \mathrm{H}$. Yasuda and I. Kobayashi, Optically stimulated luminescence from $\mathrm{Al}_{2} \mathrm{O}_{3}: \mathrm{C}$ irradiated with relativistic heavy ions, Radiat. Prot. Dosim., 2001, 95(4), 339-343.

36 A. Soni, D. R. Mishra, B. C. Bhatt, S. K. Gupta, N. S. Rawat, M. S. Kulkarni and D. N. Sharma, Thermally assisted OSL: a potent tool for improvement in minimum detectable dose and extension of dose range of $\mathrm{Al}_{2} \mathrm{O}_{3}: \mathrm{C}$, Geochronometria, 2013, 40(4), 258-265.

37 L. C. Oliveira, E. G. Yukihara and O. Baffa, MgO:Li, Ce, Sm as a high-sensitivity material for optically stimulated luminescence dosimetry, Sci. Rep., 2016, 6, 24348.

38 V. Dierolf, Electronic defect states in alkali halides: effects of interaction with molecular ions, Springer Science \& Business Media, 2003, vol. 185.

39 K. N. Shinde, S. Dhoble, H. Swart and K. Park, Basic Mechanisms of Photoluminescence, in Phosphate Phosphors for Solid-State Lighting, Springer, 2012, pp. 41-59. 